\title{
Characterization of Alpha and Beta Tubulin Genes in the Dimorphic Fungus Histoplasma capsulatum
}

\author{
By GRACE SPATAFORA HARRIS, ${ }^{\dagger} \dagger$ ELIZABETH J. KEATH ${ }^{2}$ AND \\ JUDITH MEDOFF ${ }^{1 *}$ \\ ${ }^{1}$ Department of Biology, St Louis University, St Louis, Missouri 63103, USA \\ ${ }^{2}$ Division of Infectious Diseases, Washington University School of Medicine, St Louis, \\ Missouri 63110, USA
}

(Received 24 January 1989; revised 20 March 1989; accepted 5 April 1989)

\begin{abstract}
Evidence from our laboratory indicates that microtubules are involved in the differentiation of the dimorphic, pathogenic fungus Histoplasma capsulatum; therefore, we cloned the tubulin genes from a virulent strain of the organism. We report that the $H$. capsulatum genome contains a single alpha $(T U B 1)$ and a single beta $(T U B 2)$ tubulin gene rather than the more typical multigene family which is common in even the simplest eukaryotes. Sequence data from these genes reveal a high degree of nucleotide and protein sequence conservation relative to tubulins from other species. The coding regions of $T U B 1$ and $T U B 2$ contain five and eight intervening sequences, respectively. Field inversion gel electrophoresis of $H$. capsulatum chromosome-sized DNA fragments indicates that the $T U B 1$ and $T U B 2$ genes are unlinked. Potential regulatory elements common to both genes have been identified in the $5^{\prime}$ promoter regions. These elements may direct the coordinate expression of $T U B 1$ and $T U B 2$ during differentiation. The cloning and characterization of alpha and beta tubulin genes from $H$. capsulatum provides the first description of gene structure in this widely distributed pathogenic fungus. Isolation of the tubulin genes will facilitate future studies of tubulin gene expression during the dimorphic phase transitions and clarify the role of microtubules in the differentiation process.
\end{abstract}

\section{INTRODUCTION}

Histoplasma capsulatum is a pathogenic, dimorphic fungus which causes the disease histoplasmosis. Histoplasmosis is one of the most common primary, systemic fungal infections in the Western Hemisphere and millions of people throughout the world have become infected with the organism (Edwards, 1971). The number of reported cases of disseminated histoplasmosis in individuals with AIDS is increasing steadily (Graybill, 1988). The organism exists in soil as multicellular, filamentous mycelia; however, the only form of the fungus found in infected tissue is unicellular, budding yeast (Emmons et al., 1977). Since the mycelial phase of $H$. capsulatum is nonpathogenic and only the yeast phase is parasitic (Medoff et al., 1987), factors which control the phase transition are critical for understanding pathogenicity.

The two morphological phases of the fungus can be maintained in the laboratory by appropriate manipulation of temperature and medium composition (Salvin, 1949); yeast cells grow in vitro at $37^{\circ} \mathrm{C}$ and mycelia at $25^{\circ} \mathrm{C}$. By shifting the temperature of incubation, the transition from one phase to the other is induced. This interconversion of yeast and mycelial forms provides an attractive system for studying mechanisms and regulation of eukaryotic cell differentiation.

† Present address: Department of Biology, Washington University, St Louis, Missouri 63130, USA.

Abbreviation: IVS, intervening sequence. 
Cyclic AMP (cAMP) may provide the signal which triggers morphogenesis in $H$. capsulatum (Medoff et al., 1981) as it does in other dimorphic fungi (Larsen \& Sypherd, 1974; Paveto et al., 1975; Niimi et al., 1980). Exposure of $H$. capsulatum yeast cultures to dibutyryl cAMP, or to inhibitors of cAMP phosphodiesterase, induces transformation to the mycelial phase even at the non-permissive temperature of $37^{\circ} \mathrm{C}$ (Maresca et al., 1977). Preliminary evidence from our laboratory suggests that cAMP may induce morphological change in $H$. capsulatum at the level of microtubules (Medoff \& Medoff, 1982). cAMP is known to affect the number (Porter et al., 1974), organization (Kram \& Tomkins, 1973), and function (Kirkland \& Burton, 1972) of microtubules in intact cells, and to stimulate tubulin polymerization in vitro (Steiner, 1978). Fungal antimitotic agents such as methylbenzimidazole-2-yl carbamate (MBC) bind to fungal tubulin and inhibit the polymerization of tubulin monomers into microtubules (Davidse \& Flach, 1977). In $H$. capsulatum, MBC reversibly inhibits the yeast-to-mycelia phase transition (Medoff \& Medoff, 1982), supporting the notion that microtubules are involved in $H$. capsulatum differentiation.

To extend the study of microtubule involvement during $H$. capsulatum morphogenesis, we have cloned and characterized tubulins, the major constituent proteins of microtubules, from this fungal pathogen. We report the isolation of one alpha (TUB1) and one beta (TUB2) tubulin gene as well as the nucleotide and predicted amino acid sequence for both genes.

\section{METHODS}

Strains, media and growth conditions. The low-virulence Downs strain and the highly virulent 217B strain, mating types $(-)$, of $H$. capsulatum were obtained from our permanent laboratory collection and maintained as previously described (Maresca et al., 1977).

Isolation and purification of chromosomal and plasmid DNAs. High-molecular-mass DNA from $H$. capsulatum was prepared as described by Akins \& Lambowitz (1985) for Neurospora crassa. DNAs isolated by this procedure were in excess of $48 \mathrm{~kb}$ in size. Plasmid DNAs were isolated from Escherichia coli DH5 alpha according to Maniatis $e t$ al. (1982).

Gel electrophoresis and hybridization methods. Genomic or plasmid DNAs were digested with restriction endonucleases (Promega Biotec), electrophoresed in 0.8\% or 1.0\% horizontal agarose gels in $100 \mathrm{~mm}$-Tris/borate and transferred to nitrocellulose (Schleicher \& Schuell) by the method of Southern (1975). Hybridization mixtures contained $1 \times 10^{6}$ c.p.m. $\mathrm{ml}^{-1}$ of $\left[\alpha^{-32}\right.$ P]CTP-labelled tubulin probes (Rigby et al., 1977) in $50 \%(\mathrm{v} / \mathrm{v})$ formamide, $5 \times$ Denhardt's solution, $5 \times \mathrm{SSC}$, and $25 \mathrm{~mm}$-sodium phosphate, $\mathrm{pH} 6.8$, with $200 \mu \mathrm{g}$ salmon sperm DNA ml ${ }^{-1}$ at $42{ }^{\circ} \mathrm{C}[1 \times$ Denhardt's solution is $0.02 \%$ bovine serum albumin, $0.02 \%$ Ficoll, $0.02 \%$ polyvinylpyrrolidone; $1 \times$ $\mathrm{SSC}$ is $0.15 \mathrm{M}-\mathrm{NaCl}, 0.015 \mathrm{M}$-trisodium citrate]. Low-stringency washes were performed in $2 \times \mathrm{SSC}, 0.1 \% \mathrm{SDS}$ at room temperature, and high-stringency washes in $0.2 \times \mathrm{SSC}, 0.1 \% \mathrm{SDS}$ at $50^{\circ} \mathrm{C}$.

$H$. capsulatum genomic library construction and screening. An $H$. capsulatum genomic library was constructed as described by Maniatis et al. (1982), using 13 to $20 \mathrm{~kb}$ fragments from a partial $M$ boI digest of 217B DNA. The library, constructed in the bacteriophage vector EMBL3, contained $2 \times 10^{5}$ recombinants with an average insert size of $19 \mathrm{~kb}$. A total of 10000 independent bacteriophage clones were screened in situ with [ $\left.\alpha-{ }^{32} \mathrm{P}\right] \mathrm{CTP}$-labelled tubulin-specific cDNA probes from Chlamydomonas reinhardii (provided by Bill Dove, McArdle Laboratory for Cancer Research, University of Wisconsin, Madison, WI 53706, USA) according to the method of Benton \& Davis (1977).

DNA sequence analysis. The alpha (TUB1) and beta (TUB2) tubulin genes were sequenced by the dideoxy chain termination method (Sanger et al., 1977). DNA sequences were analysed and compared using Sequence Version 2.0 (Delaney Software, Vancouver, BC, Canada).

Localization of tubulin genes to $H$. capsulatum chromosome-sized fragments. Chromosome-sized DNAs from the Downs and 217B strains were fractionated on low-percentage agarose gels by field inversion gel electrophoresis (Carle et al., 1986; Steele et al., 1989) using an embedded lysis technique adapted for Histoplasma. Resolved chromosomal DNAs were transferred to nitrocellulose membranes and hybridized as described above.

\section{RESULTS AND DISCUSSION}

\section{Isolation of genomic clones}

To identify the alpha and beta tubulin genes in the $H$. capsulatum genome, cDNA probes from Chlamydomonas reinhardii, clones alpha 253 and beta 37 (Silflow \& Rosenbaum, 1981), were used to screen an EMBL3 bacteriophage library containing genomic inserts from $H$. capsulatum 
(a) $\alpha 1.2 .2 .1$

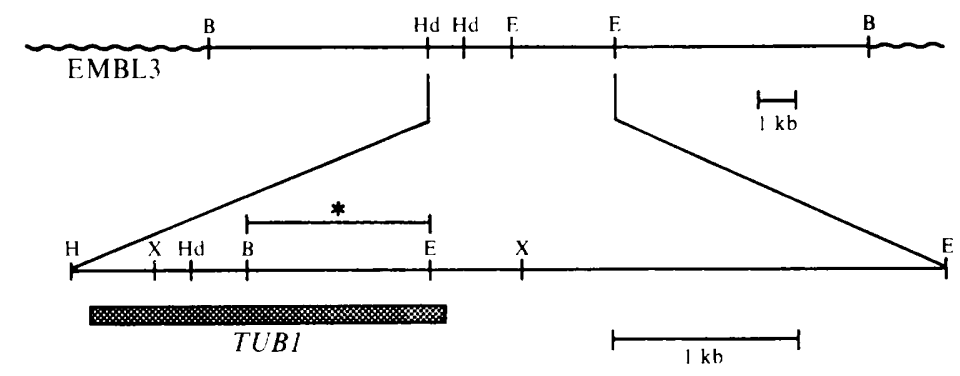

(b) $\beta 2.1 .1 .1$

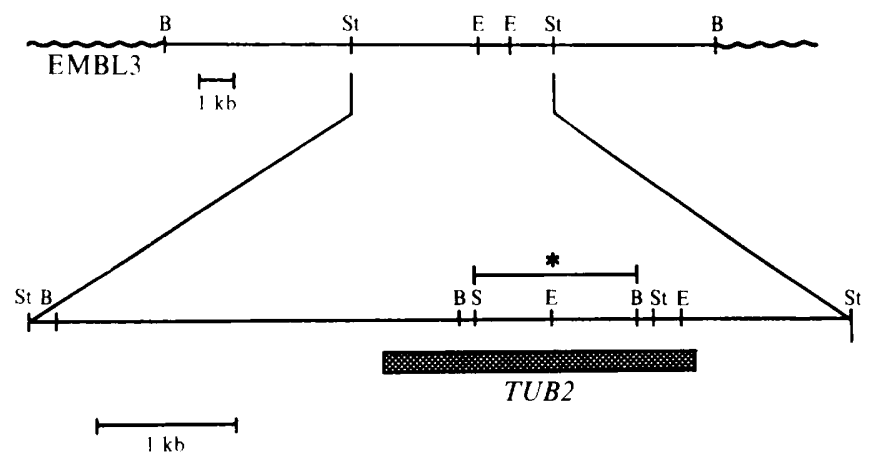

Fig. 1. Restriction maps of recombinant bacteriophages alpha 1.2.2.1 and beta 2.1.1.1, containing the alpha (TUB1) and beta (TUB2) tubulin genes from $H$. capsulatum, respectively. Alpha 1.2.2.1 contains a $17 \mathrm{~kb}$ insert of $H$. capsulatum genomic DNA cloned into the BamHI site of EMBL3; TUBI is harboured on a $1.9 \mathrm{~kb}$ fragment (stippled box). Beta 2.1 .1 .1 contains a $15.6 \mathrm{~kb}$ insert also cloned into the BamHI site of EMBL3; TUB2 is harboured on a $2.3 \mathrm{~kb}$ fragment (stippled box). The fragments designated with an asterisk (*) were nick-translated and used as probes in subsequent experiments. B, BamHI; E, EcoRI; Hd, HindIII; S, SalI; St, SstI; X, XhoI.

217B. Preliminary restriction mapping of the purified recombinant bacteriophage revealed that each set of alpha and beta phage clones contained DNAs with overlapping tubulin sequences. Thus, a single clone from each set was selected for further analysis. Figs $1(a)$ and $1(b)$ show restriction maps of the EMBL3 bacteriophage containing tubulin inserts alpha 1.2.2.1 and beta 2.1.1.1.

To test for rearrangements within the bacteriophage clones, parallel restriction digests of alpha 1.2.2.1, beta 2.1.1.1, and total $H$. capsulatum genomic DNA were compared by Southern analysis using the probes described in Fig. 1. Identical hybridization patterns were generated on the bacteriophage and genomic DNA blots, suggesting that no gross rearrangements, additions, or deletions had occurred during the cloning procedure (data not shown).

\section{Single alpha and beta tubulin genes in the $H$. capsulatum genome}

To determine the number of alpha and beta tubulin genes in the $H$. capsulatum genome, the $T U B I$ and $T U B 2$ probes were hybridized to Southern blots of restricted $H$. capsulatum genomic DNA. Hybridization at low stringency revealed unique, strongly hybridizing bands, indicating no cross-hybridization between the alpha and beta tubulin sequences (Fig. 2). Furthermore, for each restriction enzyme digest, the alpha and beta tubulin probes hybridized to one fragment, suggesting the presence of a single gene each for alpha and beta tubulin in the $H$. capsulatum genome. Prolonged exposures of these blots did not reveal any additional hybridizing bands. 

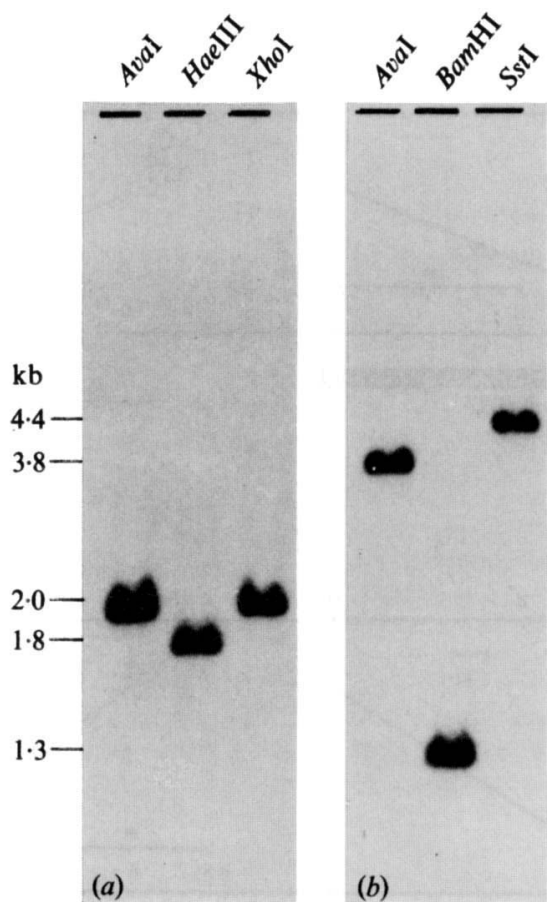

Fig. 2. Southern blot analysis to determine the number of alpha and beta tubulin genes in $H$. capsulatum. Genomic DNA of $H$. capsulatum 217B was digested with the restriction endonucleases indicated on the figure, separated on $0.8 \%$ agarose gels in Tris/borate buffer, and transferred to nitrocellulose membranes. Panels $(a)$ and $(b)$ were hybridized respectively with the alpha $(T U B I)$ and beta (TUB2) tubulin probes (see Fig. 1). The positions and lengths of the resulting DNA fragments are indicated on the left. The detection of one hybridizing band for each restriction digest confirms the presence of a single gene each for alpha and beta tubulin in the $H$. capsulatum genome.

Confirmation of the identities of the alpha $(T U B 1)$ and beta (TUB2) tubulin-specific sequences in $H$. capsulatum was obtained by DNA sequence analysis. It is likely that $T U B I$ and $T U B 2$ represent the entire complement of tubulin genes in $H$. capsulatum since no additional sequences with homology to either alpha or beta tubulin have been detected, even when homologous probes were utilized under very low-stringency hybridization conditions.

In all but the simplest eukaryotes, multiple tubulin genes are required for the construction and maintenance of essential microtubules (for review, see Cleveland \& Sullivan, 1985). Significantly fewer tubulin genes have been described and cloned in lower eukaryotes. Two alpha and two beta tubulin genes have been detected in the filamentous fungus Aspergillus nidulans (Weatherbee \& Morris, 1984), and two alpha tubulin genes and one beta tubulin gene have been identified in the fission yeast Schizosaccharomyces pombe (Hiraoka et al., 1984; Toda et al., 1984), and in the budding yeast Saccharomyces cerevisiae (Neff et al., 1983; Schatz et al., 1986). The ciliated protozoon Tetrahymena contains a single alpha tubulin gene (Callahan et al., 1984).

The presence of a single alpha (TUB1) and a single beta (TUB2) tubulin gene in $H$. capsulatum is unique among eukaryotes so far investigated, but consistent with the findings in Schizosaccharomyces pombe and Saccharomyces cerevisiae, where two alpha tubulin genes and one beta tubulin gene have been described. Transformation-mediated gene-disruption experiments have shown that although these yeasts have multiple tubulin gene families, only a single alpha and a single beta tubulin gene are required to perform all the functions that have been attributed to microtubules in the yeast life cycle (Adachi et al., 1986; Schatz et al., 1986). The function of the non-essential alpha tubulin gene in these fungi remains uncertain. 


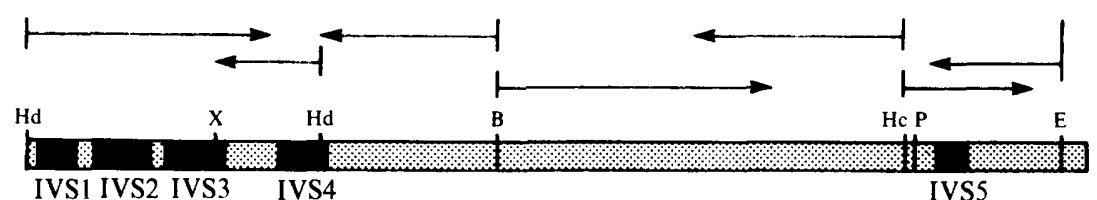

TUB 2

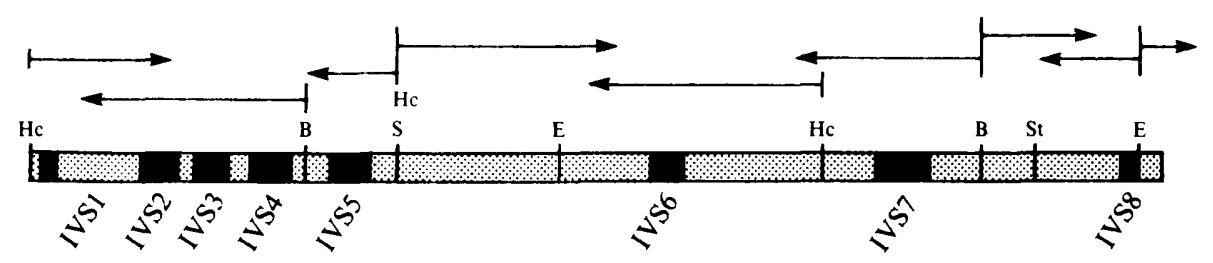

Fig. 3. Structural organization of the $H$. capsulatum alpha (TUB1) and beta (TUB2) tubulin genes. Each gene was sequenced by the dideoxynucleotide chain termination method to the extent, and in the direction, indicated by the arrows. Much of the sequence information for these genes was generated from a single subclone in a single direction. The $H$. capsulatum $T U B 1$ nucleotide sequence was over $75 \%$ homologous to alpha tubulins from Saccharomyces cerevisiae (Schatz et al., 1986), Schizosaccharomyces pombe (Toda et al., 1984) and Chlamydomonas reinhardii (Silfow et al., 1985). The nucleotide sequence generated for $T U B 2$ was $84 \%$ conserved relative to beta tubulins from Aspergillus nidulans (May et al., 1987), Neurospora crassa (Orbach et al., 1986), Saccharomyces cerevisiae (Neff et al., 1983) and Chlamydomonas reinhardii (Youngblom et al., 1984). TUBI and TUB2 coding regions are denoted by the stippled areas, and black boxes indicate the locations of the predicted intervening sequences (IVSs). Restriction endonucleases are abbreviated as in Fig. 1, plus: Hc, HincII; P, PstI.

\section{Alpha (TUB1) and beta (TUB2) tubulin gene structure}

Since $H$. capsulatum uses the products of a single alpha and a single beta tubulin gene for diverse microtubular functions as well as differentiation, the organization and sequence of its tubulin genes are of interest. TUB1 and TUB2 were sequenced using the strategy outlined in Fig. 3. This strategy was adopted since the primary amino acid sequence of alpha and beta tubulins from even remotely related species is highly conserved (Cleveland \& Sullivan, 1985).

The proposed introns for $T U B 1$ and $T U B 2$ were identified as gaps in the protein homology between the translated $H$. capsulatum genes and other highly conserved alpha and beta tubulin protein sequences. Based on this analysis, the predicted coding regions of $T U B 1$ and $T U B 2$ were interrupted by five and eight intervening sequences (IVSs) respectively (Fig. 3). Like other fungal tubulin introns, the $H$. capsulatum $T U B 1$ and $T U B 2$ IVSs are relatively short, ranging from $42 \mathrm{bp}$ for IVS8 (TUB2) to $113 \mathrm{bp}$ for IVS3 (TUB1), and contain consensus splice junctions similar to those found in other nuclear eukaryotic genes (Mount, 1982). Furthermore, twelve of the thirteen IVSs contain an adenosine residue within an internally-conserved sequence, resembling the yeast TACTAAC consensus sequence (Langford $e t$ al., 1984) which mediates the splicing event (Ruskin et al., 1984). In H. capsulatum, the internal element is located near the $3^{\prime}$ end of each IVS, beginning 18 to 32 nucleotides upstream of the $3^{\prime}$ splice junction.

The IVS positions within TUB1 and TUB2 are highly conserved when compared to the organization of other fungal tubulin genes. Five of the eight beta tubulin IVSs in Histoplasma (Fig. 5) occur at the same positions (after codons 4,12 and 53, and splitting codons 21 and 35) as those of Neurospora (Ohrbach et al., 1986) and Aspergillus (May et al., 1987). The other three IVSs in TUB2 are localized to codons 206, 318 and 438, each just one codon away from the intron positions described for the ben $A$ beta tubulin gene of Aspergillus (May et al., 1987). Furthermore, one of the five alpha tubulin IVSs in $H$. capsulatum (Fig. 4) occurs at the same position as the 


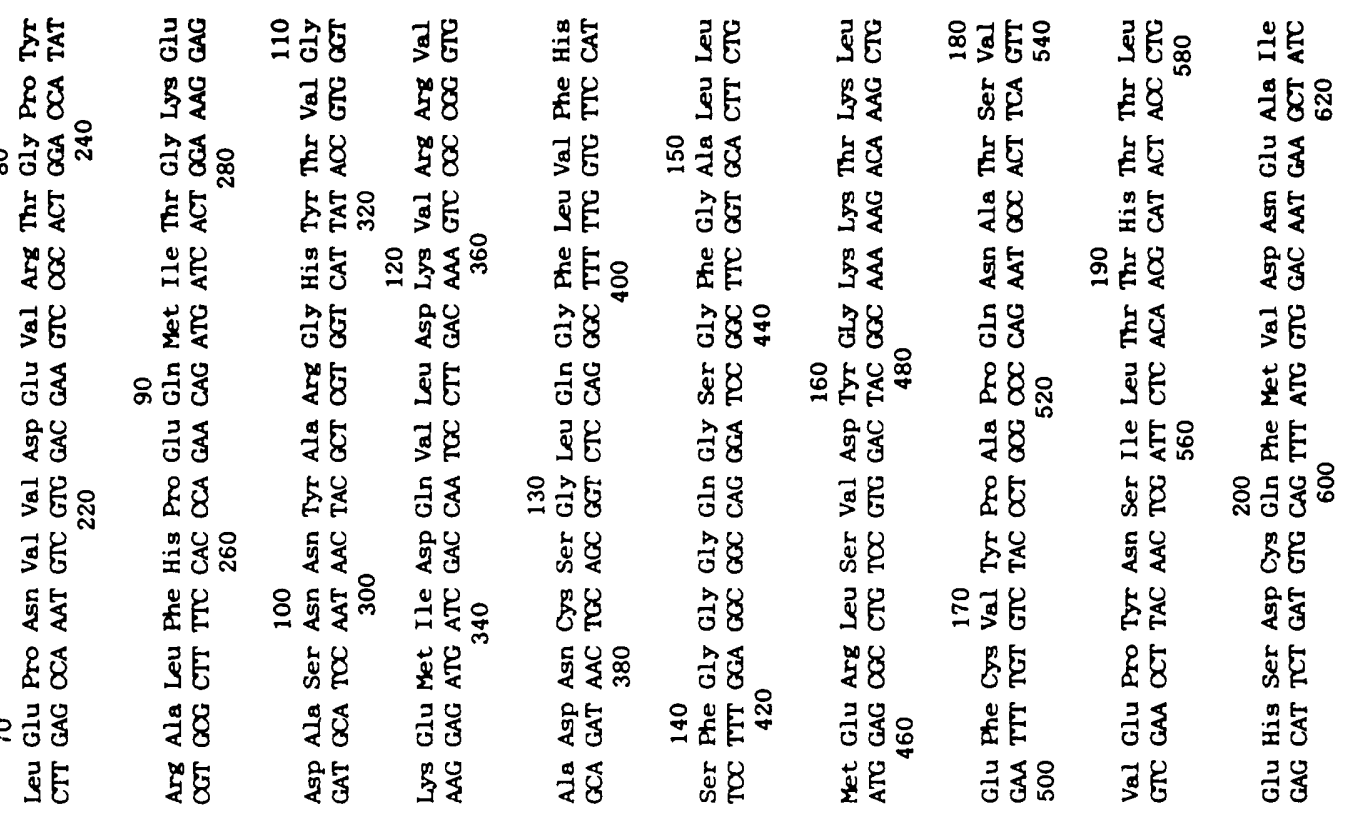

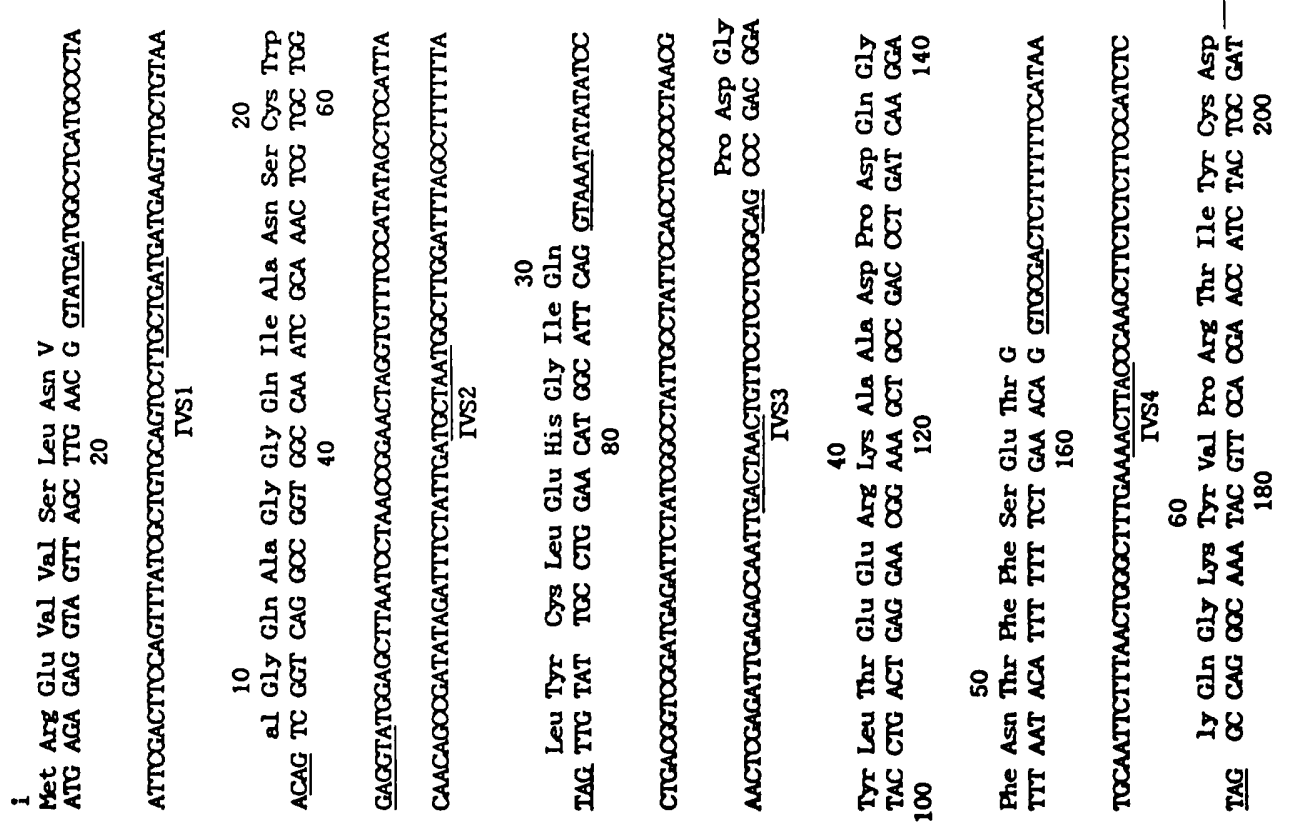




\begin{tabular}{|c|c|c|c|c|c|}
\hline 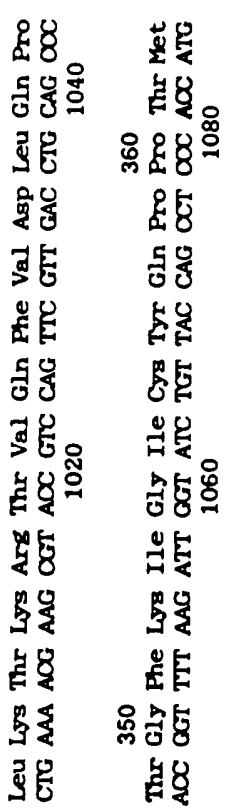 & 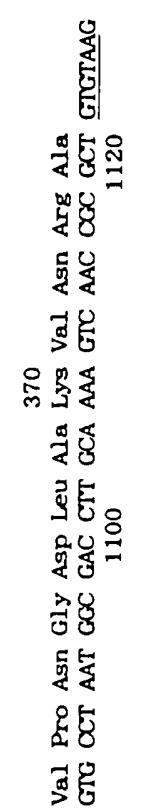 & 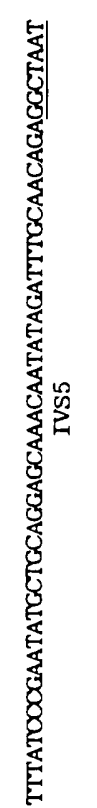 & 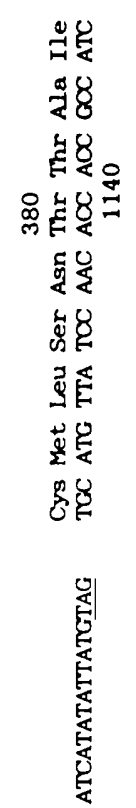 & 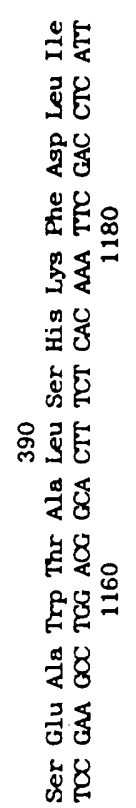 & 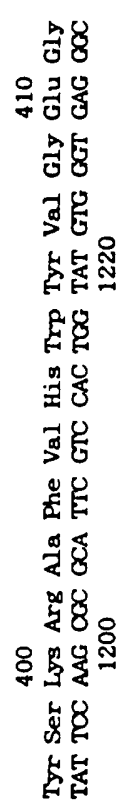 \\
\hline
\end{tabular}

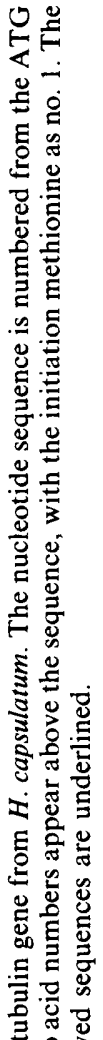

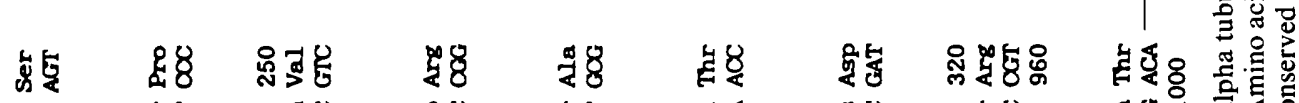

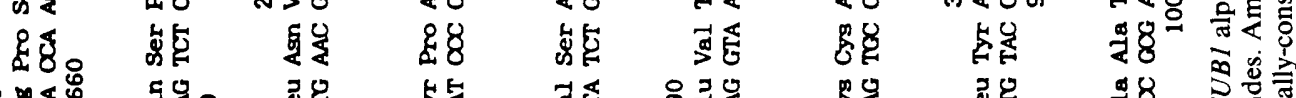

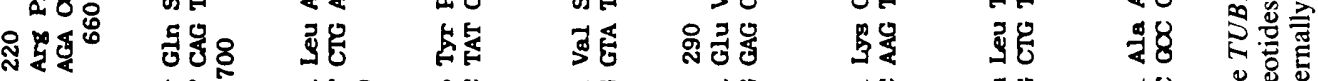

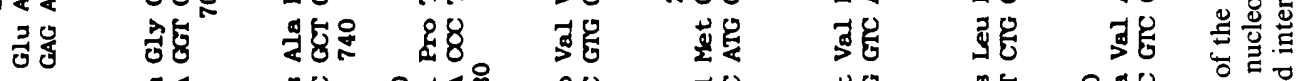

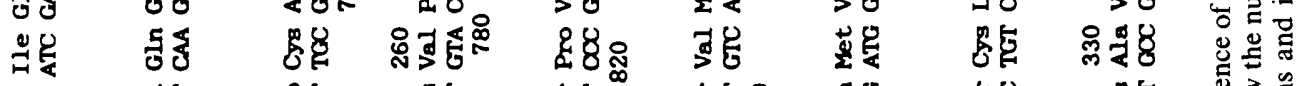

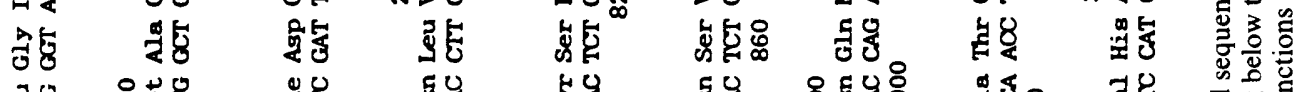

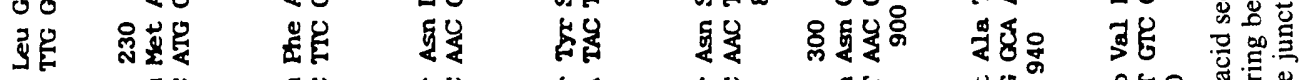

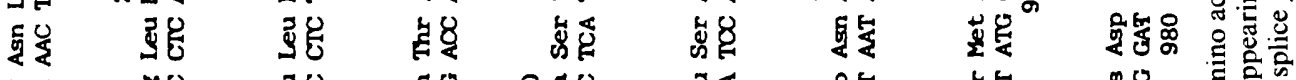

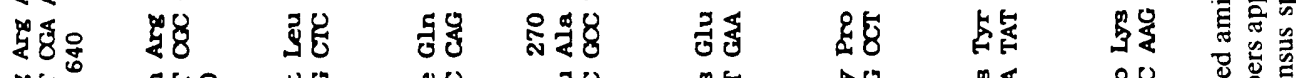

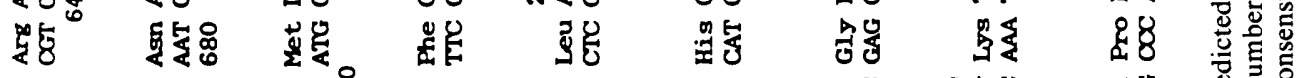

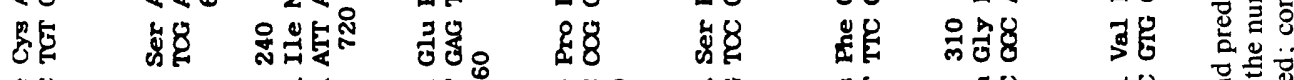

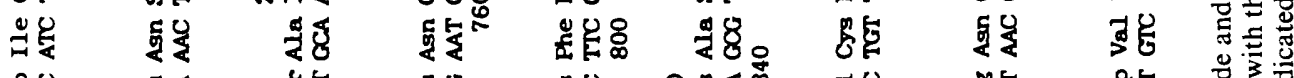

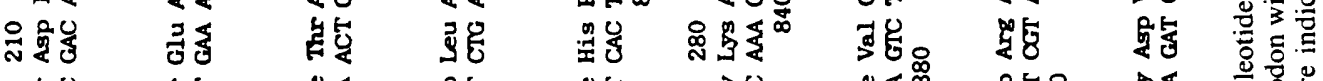

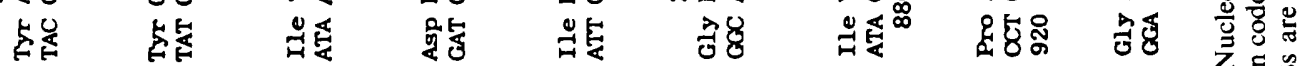

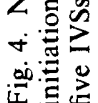




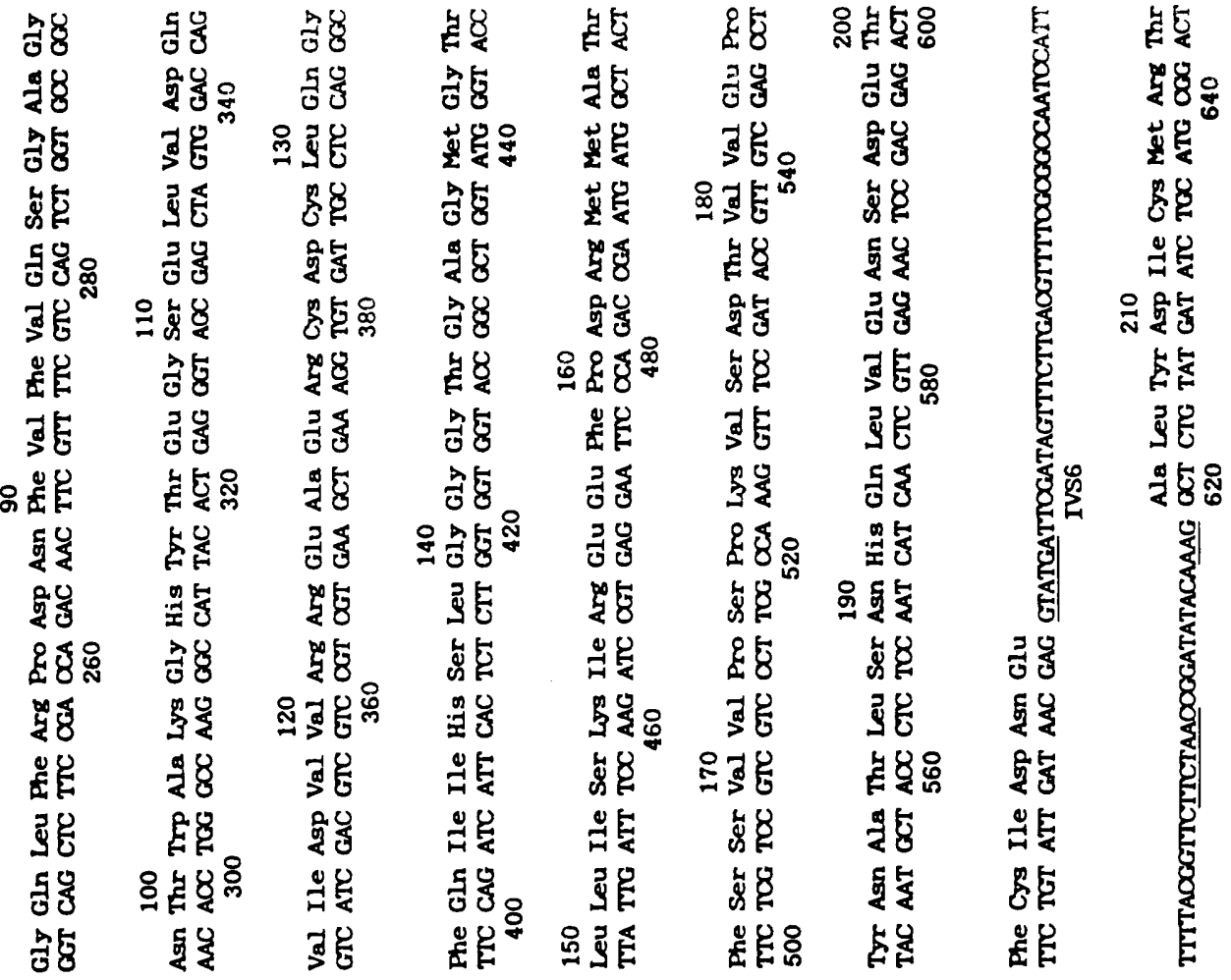
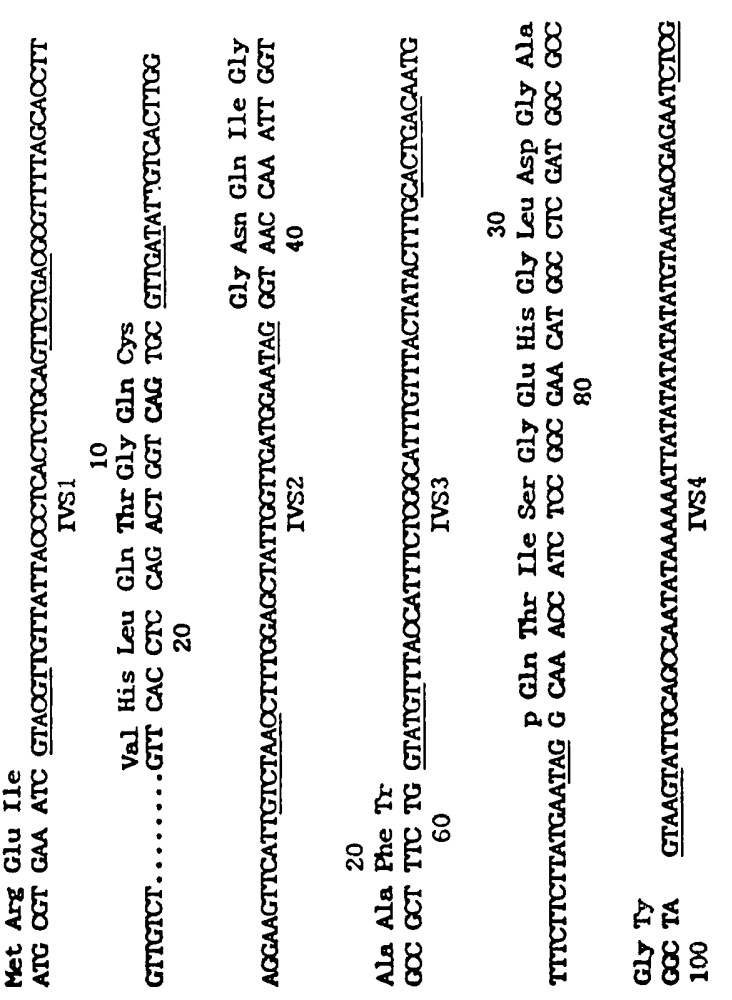

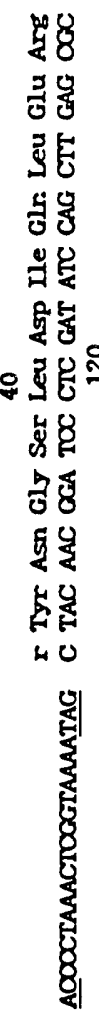

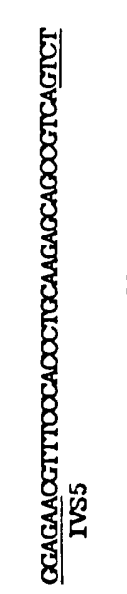

牙最 品

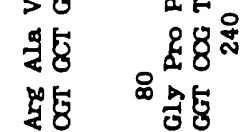

\&ष्ठ

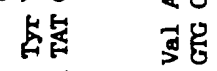

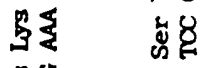

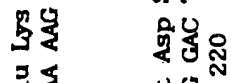

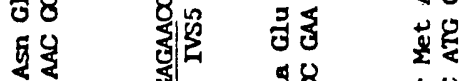

है क्षे दर्ष

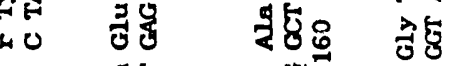

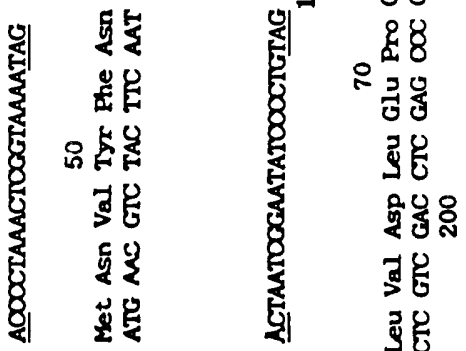




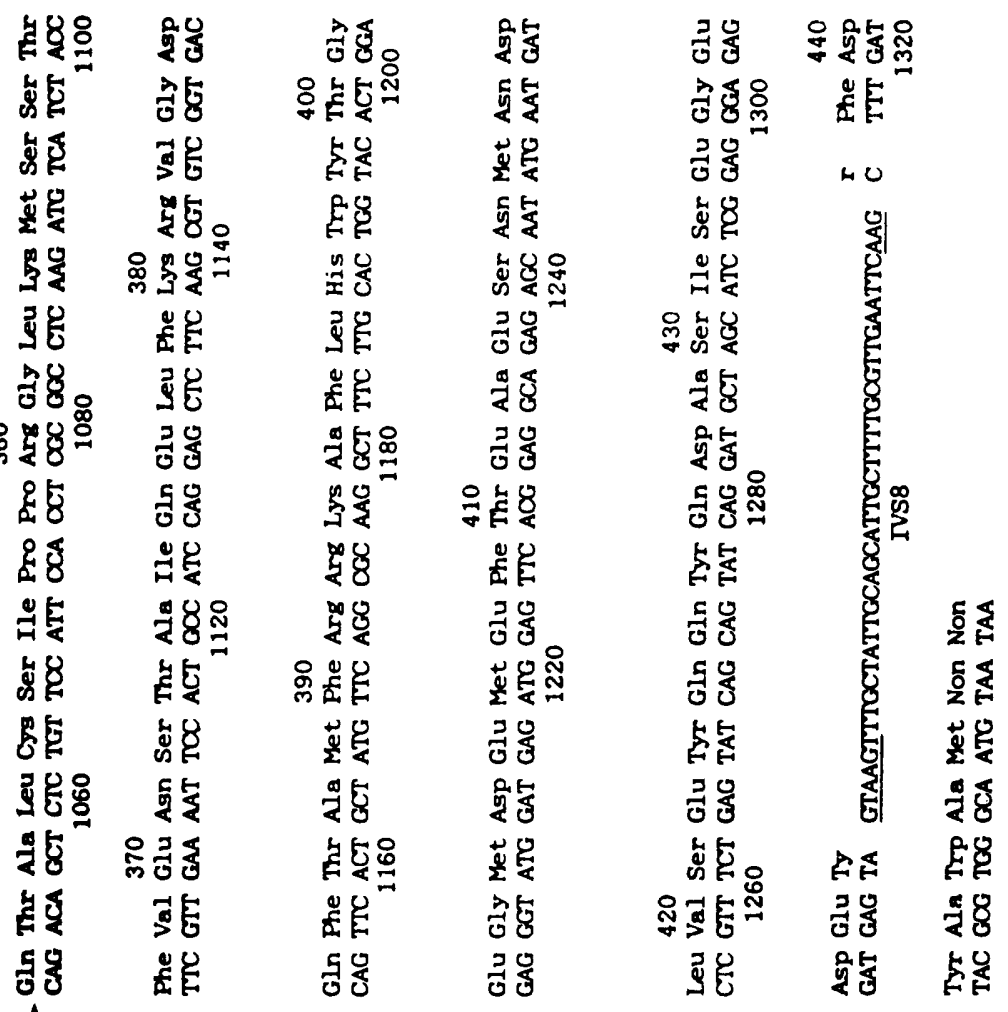

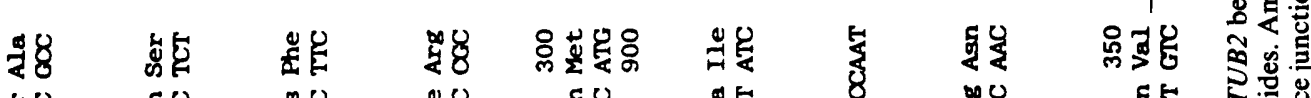

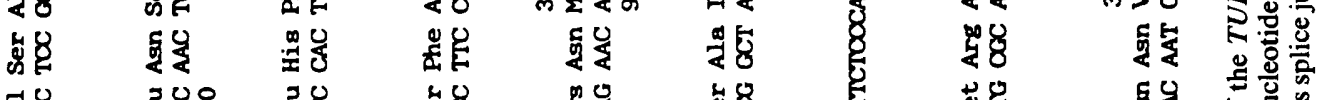

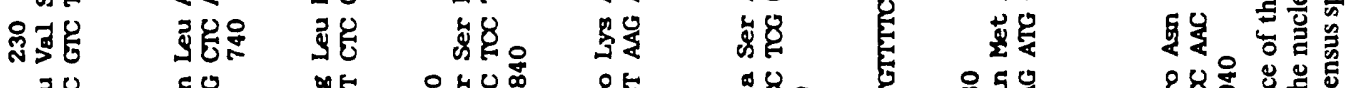

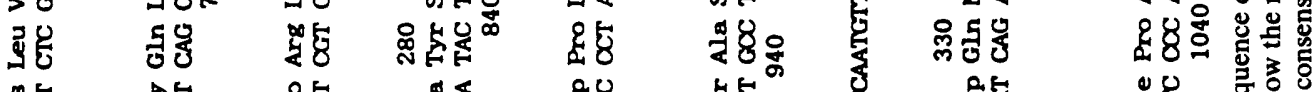

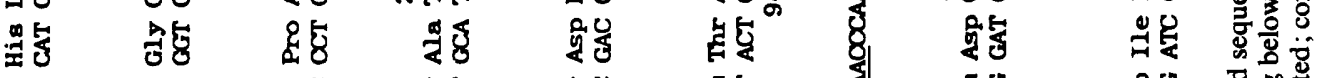

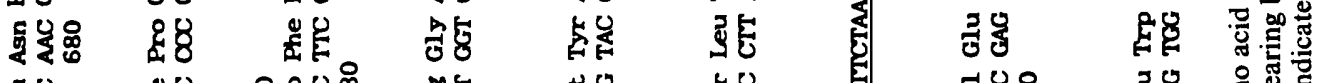

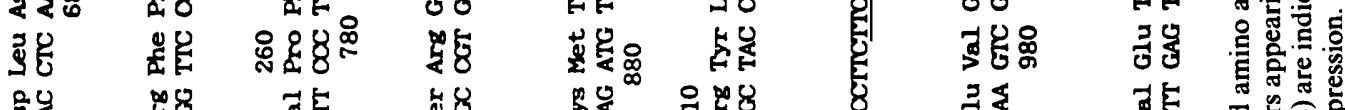

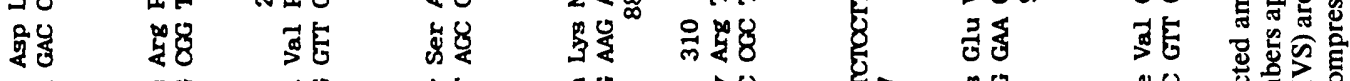

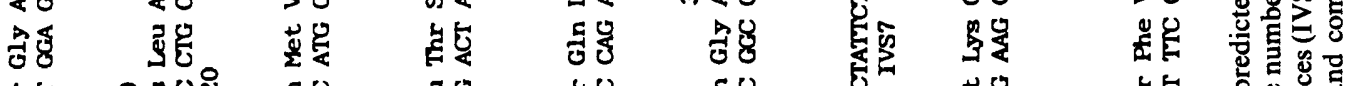

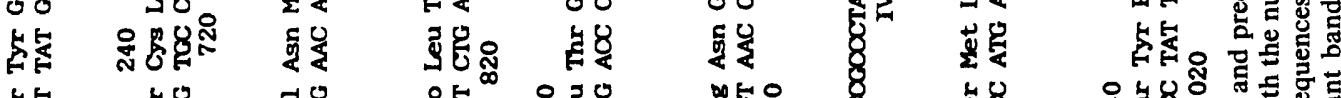

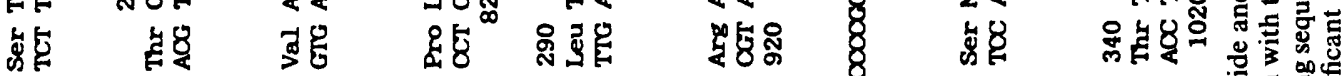

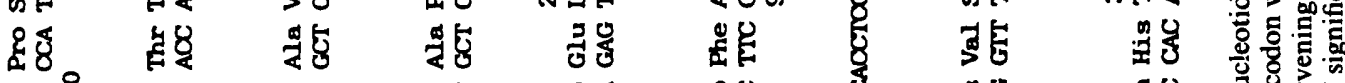

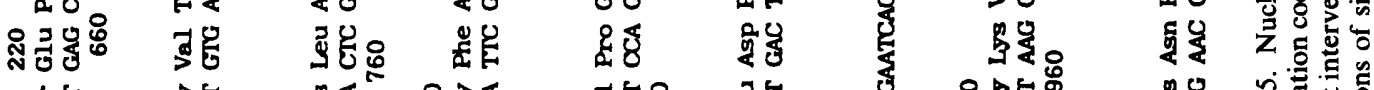

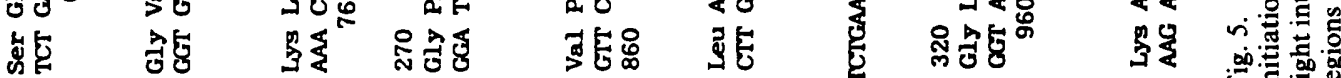

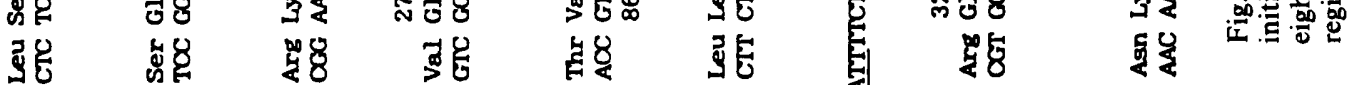

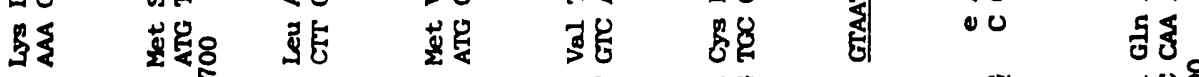

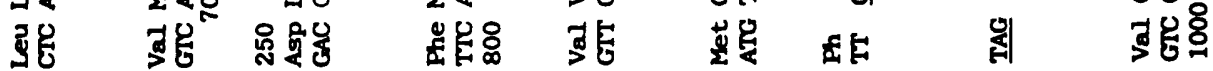


single intron found in the alpha tubulin genes of Saccharomyces cerevisiae (Schatz et al., 1986). A second intervening sequence in $T U B 1$ occurs after codon 21 , a position very near that of the sole intron which interrupts the alpha 1 tubulin gene of Schizosaccharomyces pombe (Toda et al., 1984).

The DNA and predicted amino acid sequences for the alpha and beta tubulin genes of $H$. capsulatum are presented in Figs 4 and 5 respectively. The sequences confirm the identity of the cloned genes, distinguish different functional regions of the tubulin molecules, and identify potential regulatory elements in the $5^{\prime}$ promoter regions. Fig. 4 shows 1251 bp of the coding region of the $T U B I$ gene. The gene was sequenced up to the EcoRI site (Fig. 3) and all but the last 25 to 30 amino acid residues at the carboxyl terminus have been identified (Fig. 6). The complete sequence of beta tubulin is shown in Fig. 5. The coding region of TUB2 contains $1335 \mathrm{bp}$, which predicts a protein of 445 amino acids. The calculated molecular mass of beta tubulin is $58159 \mathrm{Da}$, a value in close agreement with other fungal beta tubulins (May et al., 1987).

\section{Significance of conserved and heterogeneous regions in the primary sequence}

Sequence comparisons among ascomycetous tubulin genes indicate conserved regions in Aspergillus (May et al., 1987), Neurospora (Orbach et al., 1986) and Histoplasma tubulin genes which underscore a common functional role. All three fungi share a conserved sequence, KYVPRA, at amino acids 58-64 for beta tubulin (Fig. 7). For alpha tubulin, five of the six amino acid residues are conserved in a similar region (Fig. 6). This sequence resembles a GTP-binding domain required for the polymerization of tubulin monomers into microtubules (Weisenberg, 1972), and has been found in many tubulins and GTP-binding proteins (Leberman \& Egner, 1984). The beta tubulin genes of Aspergillus, Neurospora and Histoplasma also share a conserved HSLGGGTGAGMGTLL sequence spanning amino acids 138-152 (Fig. 7) resembling a phosphate-binding pocket which is also present in other tubulins and nucleotide-binding proteins (Krauhs et al., 1981; May et al., 1987). Alpha tubulin has a similar conserved sequence containing a cluster of glycines in the same region (Fig. 6) which may represent a flexible loop involved in phosphate binding (Krauhs et al., 1981).

The majority of the nucleotide differences present in the $H$. capsulatum alpha and beta tubulin sequences occur at the third position of a codon and do not change the predicted amino acid. The differences in amino acids that do occur, however, appear to be clustered within the primary sequence. As seen in Fig. 6, a variable domain in the $T U B I$ gene spans amino acid residues 35 to 50 , near the amino terminus of the protein molecule. Another major region of heterogeneity exists at the extreme carboxyl terminus of the TUB2 protein (Fig. 7). Serrano et al. (1984a) suggested that the carboxy-terminal domain of the tubulin molecule is involved in binding the microtubule-associated protein, MAP-2, which regulates tubulin assembly, yet in vitro experiments demonstrate that proteolytic removal of the carboxyl terminus does not prevent self-assembly (Serrano et al., 1984b). Recent evidence from Saccharomyces cerevisiae also suggests that insertions into the amino-terminal variable region do not disrupt tubulin function in vivo (Schatz et al., 1987). The biological significance of this and other heterogeneous domains in $H$. capsulatum remains uncertain.

\section{Localization of tubulin genes to $H$. capsulatum chromosomes}

Electrophoretic separation of large, chromosome-sized DNA molecules has proved useful in establishing the linkage relationship between alpha and beta tubulin genes in yeast (Schwartz \& Cantor, 1984). Field inversion gel electrophoresis, a technique which resolves chromosomal DNAs in an alternating electric field, was applied to $H$. capsulatum. Four chromosome-sized DNA bands were resolved by this method in the Downs strain of $H$. capsulatum, and two in the more virulent 217B strain (Fig. 8a). These large DNA molecules are chromosome-like since they migrate as discrete bands to a size range comparable with the known chromosomes of Saccharomyces cerevisiae and Schizosaccharomyces pombe (Schwartz \& Cantor, 1984). Since classical genetics have not been performed with this fungal pathogen, however, it is unclear whether the chromosome-sized DNAs resolved at these conditions represent all of the nuclear chromosomes present in $H$. capsulatum. 


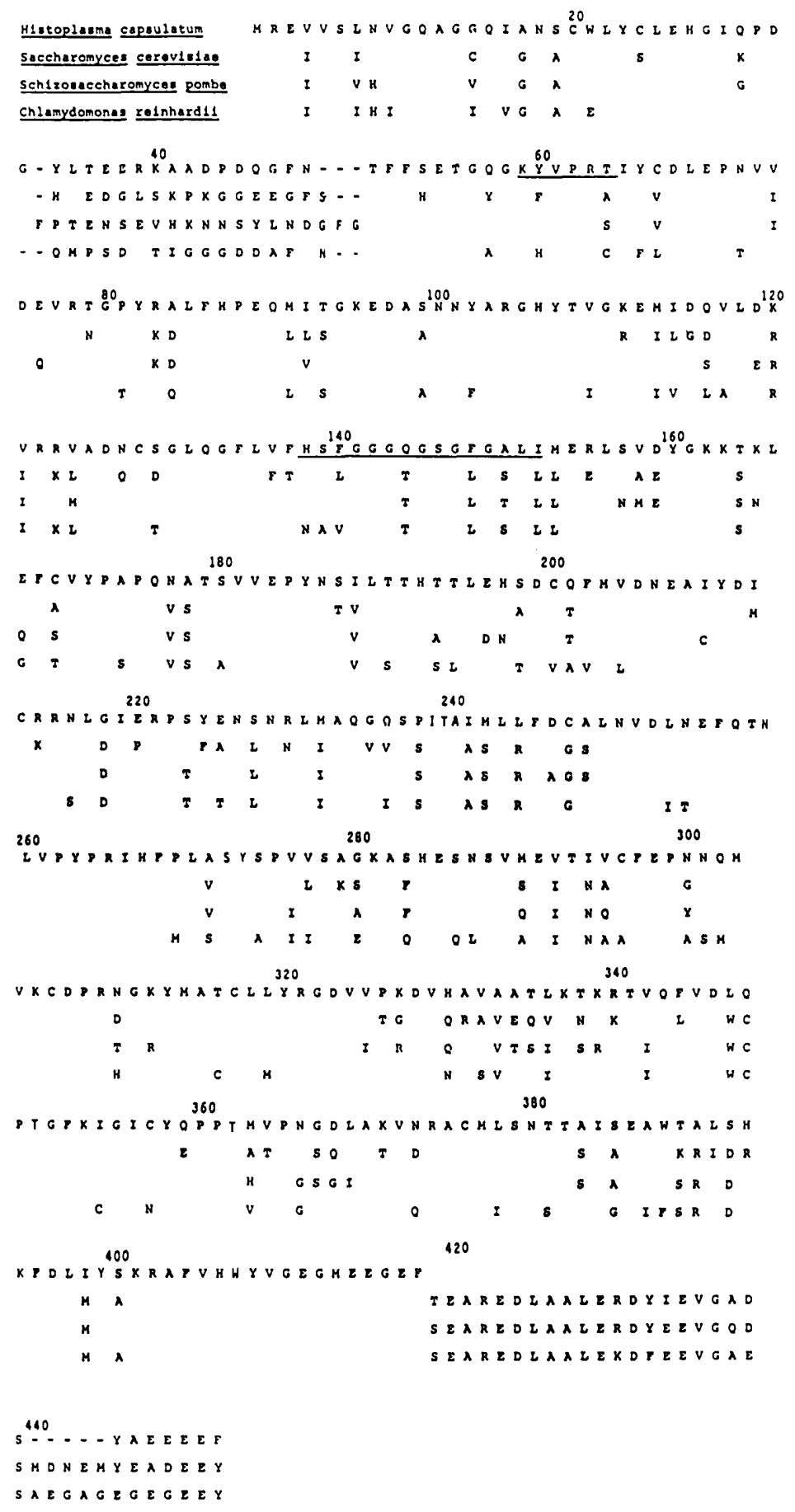

Fig. 6. Alpha tubulin protein sequence comparisons. The $T U B 1$ amino acid sequence from $H$. capsulatum is shown in one-letter code and compared with the alpha tubulin protein sequences of Saccharomyces cerevisiae (Schatz et al., 1986), Schizosaccharomyces pombe (Toda et al., 1984) and Chlamydomonas reinhardii (Silflow et al., 1985). Only amino acids that differ from those of the $H$. capsulatum sequence are indicated. Dashes have been inserted into the sequences to bring them into register. The $H$. capsulatum sequence underlined near amino acid residue 60 resembles a GTP-binding domain. The underlined region near amino acid residue 140 is a putative phosphate-binding pocket. 


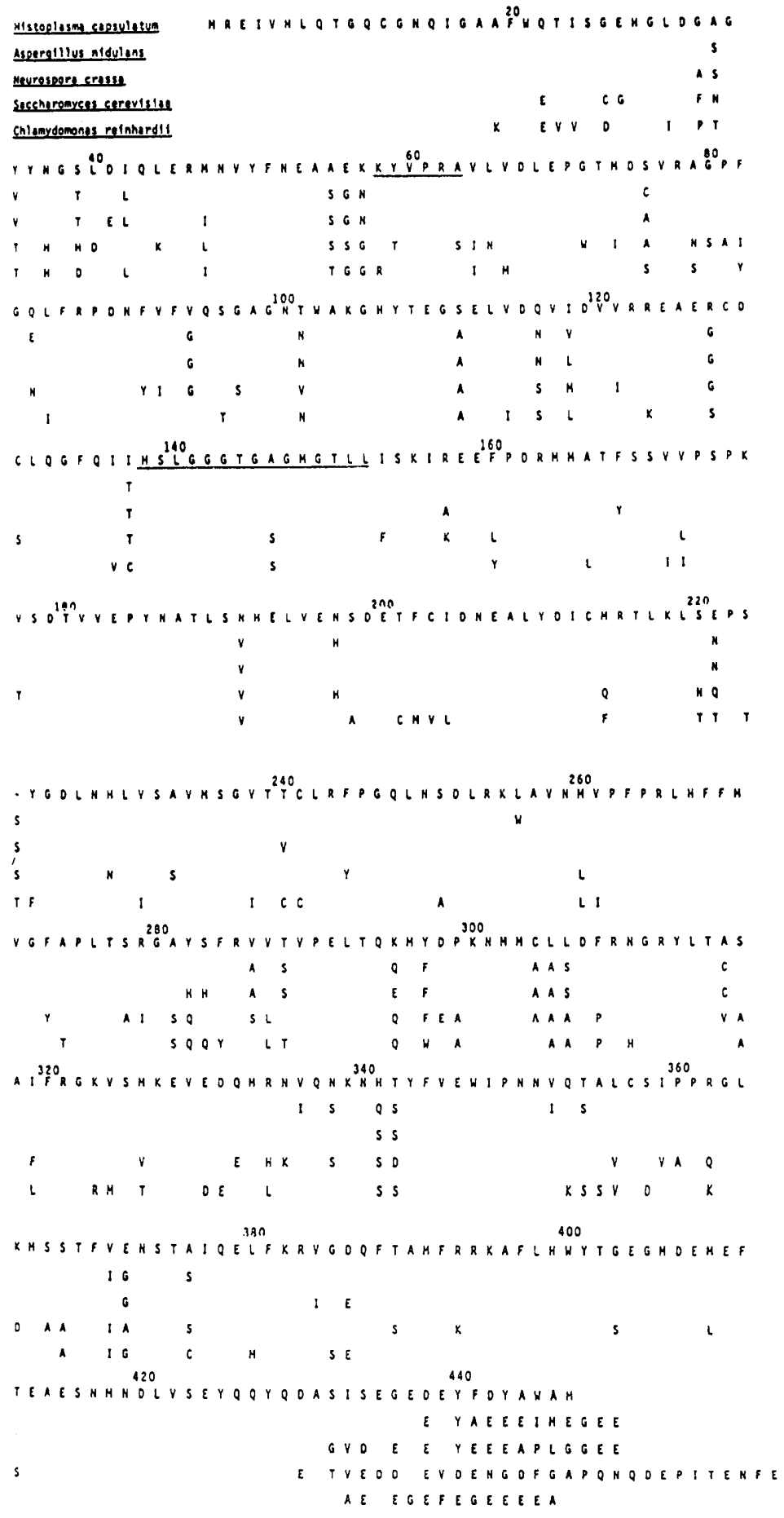

Fig. 7. Beta tubulin protein sequence comparisons. The $T U B 2$ amino acid sequence from H. capsulatum is shown in one-letter code and compared with the beta tubulin protein sequences of Aspergillus nidulans (May et al., 1987), Neurospora crassa (Orbach et al., 1986), Saccharomyces cerevisiae (Neff et al., 1983) and Chlamydomonas reinhardii (Youngblom et al., 1984). Only amino acids that differ from those of the $H$. capsulatum sequence are indicated. The sequences underlined near amino acid residues 60 and 140 resemble a GTP-binding domain and a phosphate binding pocket, respectively. 


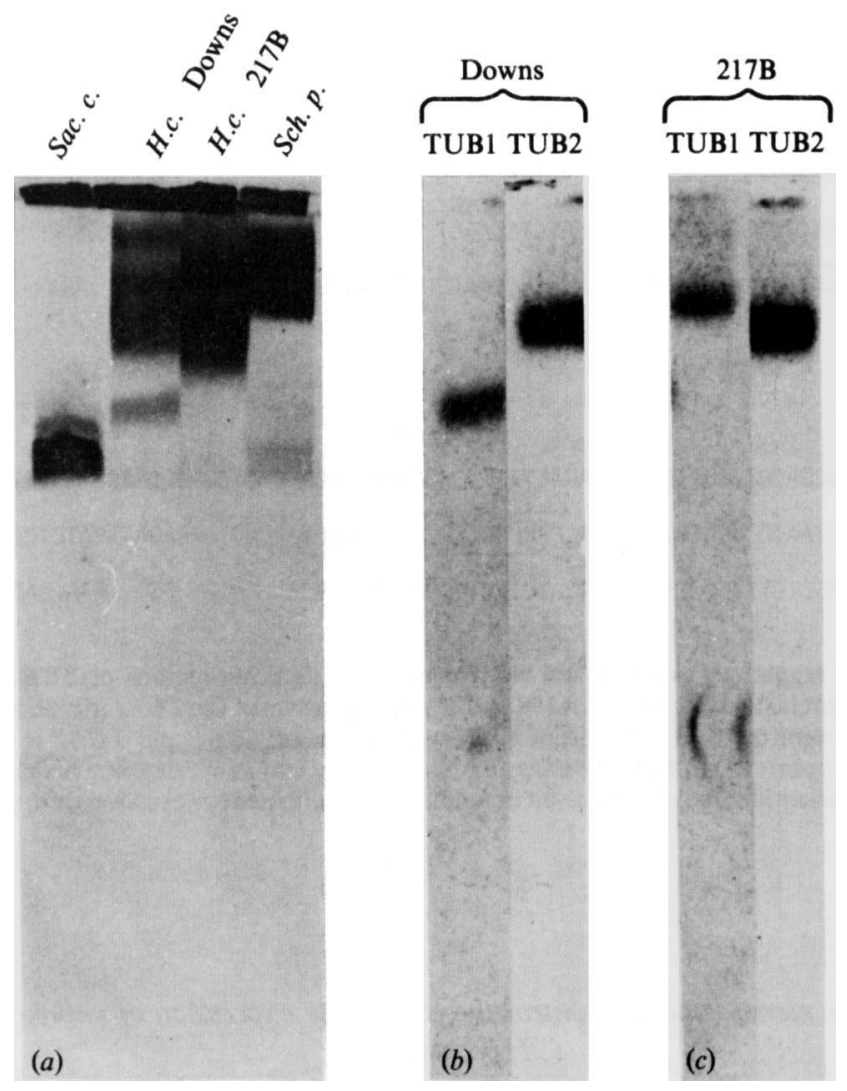

Fig. 8. Localization of tubulin genes on $H$. capsulatum chromosome-sized molecules. Chromosomesized DNAs were fractionated on low-percentage agarose gels by field inversion gel electrophoresis. The ethidium bromide stained gel shown in (a) permitted direct comparison of $H$. capsulatum chromosome-sized bands with chromosomes of known size from Saccharomyces cerevisiae (Sac. c.) and Schizosaccharomyces pombe (Sch. p.). Chromosomal DNAs from the Downs $(b)$ and $217 \mathrm{~B}(c)$ strains of $H$. capsulatum were blotted onto nitrocellulose filters and hybridized with the alpha $(T U B I)$ and beta (TUB2) tubulin probes (see Fig. 1). The alpha and beta tubulin genes hybridized to different chromosome-sized molecules, and therefore appear to be unlinked in both strains of $H$. capsulatum.

Southern blot analysis with the cloned tubulin genes revealed that the alpha and beta genes are located on different chromosomes in both $H$. capsulatum strains. The TUB1 probe hybridized to the lowermost chromosome-sized band in the $H$. capsulatum Downs strain, while TUB2 clearly hybridized to a different chromosome-sized molecule (Fig. $8 \mathrm{~b}$ ). The organization of $T U B I$ and $T U B 2$ on chromosomes in $H$. capsulatum $217 \mathrm{~B}$ is less obvious, however, since only two chromosome-sized molecules were resolved by field inversion in this strain, and since $T U B I$ and $T U B 2$ hybridized to a common band. This result most likely represents hybridization of the tubulin probes to different but comigrating chromosomes. Close analysis of the blots in Fig. 8(c) reveals that the $T U B 1$ probe hybridized to the uppermost portion of this band $(3.5 \mathrm{~cm}$ from the origin), while $T U B 2$ hybridized to the lower portion $(4.0 \mathrm{~cm}$ from the origin). Since both hybridizations were performed sequentially on the same filter, one may conclude that the alpha and beta tubulin genes are unlinked in the H. capsulatum 217B strain, as they are in the Downs strain. These findings are consistent with observations in Chlamydomonas (Brunke et al., 1984), and Physarum (Schedl et al., 1984). 
TUB1

ATGTGATTGCAGAAGCTTGCTGCCCAGCCAACCCCGTGCGTTCCCCGCTAGTAGAGATCGTCCGCTGCAGAGTGTACTGCACTCTGGCTCCGTTA CGGGATACAATGCCATACAGAGTACACCACGTTACGCACCTCTTG:CCAACAAGACGAACCTGAGGTCTATTTATTCTTGACCAGCTGTTCCTAT CTCATCCCATCTTGCTTCACATTAGTTAGCTCTCAACACTAAACTTGCTGGGTAATTGCCCIATCTAÄTGCTCTAACCGTCATTCTACTTTCTT TGTGTGAGATAGGTTCGGCTCTAACCAGAAGTGCAGCAGCTCCAGGTTTTGCTTGTGTCGAAGCTTCGCGAACTCCCCCATTCTTACCGTTGGG'́

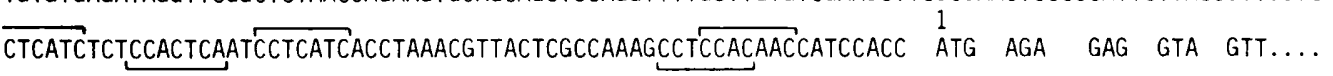

$T U B 2$

TCACGTGG TGTTCAGACAGCGACGTTAGTTCAACTGAGACTAGTGCAACAACACAGAGCCCCCGTCCCAACCTGGTTTGTTTCTCCTCC TGTTCT TCTGTTTCTCACCGCTTTCTAATCCATCCACCACACACCACCACCTCCAACACCACTACCACTACGAGATACATCTCCCATCTGCCTGCTTGACA

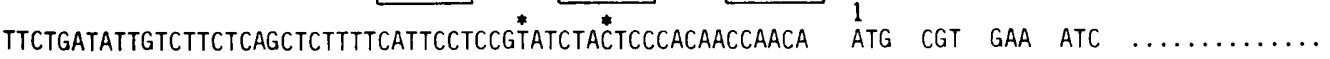

Fig. 9. Potential regulatory elements are evident in the $5^{\prime}$ flanking regions of $T U B I$ and $T U B 2$. A TATA-like element (asterisks) is present 194 nucleotides upstream of the $T U B 1$ initiation codon, and 20 nucleotides upstream of the TUB2 initiator. Also upstream of $T U B 1$ and $T U B 2$ is a $7 \mathrm{bp}$ element (brackets) which occurs in multiple copies both intermittently and in overlapping arrangements. These repeated heptanucleotides may be involved in regulating tubulin gene expression during $H$. capsulatum morphogenesis.

Potential regulatory elements which control the coordinate expression of unlinked tubulin genes in H. capsulatum

The arrangement of alpha and beta tubulin genes on different chromosomes in $H$. capsulatum raises the question of how tubulin gene expression is controlled during differentiation. The analysis of tubulin-specific mRNAs during $H$. capsulatum morphogenesis reveals that alpha and beta tubulin gene expression is induced coordinately in response to temperature shift (Harris et al., 1989). Coordinate gene regulation in this fungus may imply the presence of common regulatory features which direct the synchronous response. Intermittent and overlapping stretches of repetitive elements can be noted in the upstream region of the $H$. capsulatum $T U B 2$ gene, which are shared in the $5^{\prime}$ region of the $T U B 1$ gene. The putative regulatory element upstream of $T U B 2$ (CCACCAC) is repeated six times with few nucleotide substitutions (Fig. 9). A similar 7 bp element is repeated five times in the upstream regulatory region of the $T U B I$ gene. The nucleotide sequence of the $T U B I$ element is variably divergent, however, at the third, fifth and sixth base positions (Fig. 9). The tight clustering and frequent overlapping of these putative regulatory sequences in the $5^{\prime}$ flanking regions of the TUBI and TUB2 genes of $H$. capsulatum is reminiscent of the promoter region associated with the coordinately-regulated tubulin genes of Chlamydomonas reinhardii (Brunke et al., 1984).

Other elements with putative regulatory significance in $H$. capsulatum include a TATA-like element which is located $194 \mathrm{bp}$ upstream of the $T U B 1$ initiation methionine, and $20 \mathrm{bp}$ upstream of the $T U B 2$ initiator.

\section{Concluding remarks}

The environmentally-controlled interconversion of $\boldsymbol{H}$. capsulatum yeast and mycelial forms provides an attractive system for studying eukaryotic cell differentiation and modes of gene expression. As a first step toward investigating the role of microtubules during the morphological differentiation of $H$. capsulatum, the alpha $(T U B 1)$ and beta $(T U B 2)$ tubulin 
genes have been cloned and characterized. The finding that conserved and overlapping sequences are common in the upstream regions of the single alpha and beta tubulin genes of $H$. capsulatum suggests a potential mechanism for coordinate gene expression. Future investigations will focus on elucidating the regulatory mechanisms that underlie specific programs of tubulin gene expression during the $H$. capsulatum morphogenetic process.

We are grateful for the support and encouragement of Dr Gerald Medoff in whose laboratory this work was conducted. We also thank Dr Paul Steele and Dr Eric Spitzer for helpful discussions, and Dr George Kobayashi for his advice and assistance. Work by G.S.H. was submitted in partial fulfilment of the requirements for the $\mathrm{PhD}$ in Biology at St Louis University.

This research was supported by Medical Mycology Grant AI-16228-09 from the National Institutes of Health.

\section{REFERENCES}

Adachi, Y., Toda, T., Niwa, O. \& Yanagida, M. (1986). Differential expressions of essential and nonessential alpha tubulin genes in Schizosaccharomyces pombe. Molecular and Cellular Biology 6, 21682178.

Akins, R. A. \& Lambowitz, A. M. (1985). General method for cloning Neurospora crassa nuclear genes by complementation of mutants. Molecular and Cellular Biology 5, 2272-2278.

Benton, W. D. \& Davis, R. W. (1977). Screening lambda gt 11 recombinant clones by hybridization to single plaques in situ. Science 196, 180-181.

Brunke, K. J., Anthony, J. G., Sternberg, E. J. \& WeEKS, D. P. (1984). Repeated consensus sequence and pseudopromoters in the four coordinately regulated tubulin genes of Chlamydomonas reinhardii. Molecular and Cellular Biology 4, 1115-1124.

Callahan, R. C., Shalke, G. \& Gorovsky, M. A. (1984). Developmental rearrangements associated with a single type of expressed $\alpha$-tubulin gene in Tetrahymena. Cell 36, 441-445.

Carle, G. F., Frank, M. \& Olson, M. V. (1986). Electrophoretic separation of large DNA molecules by periodic inversion of the electric field. Science 232, 65-68.

Cleveland, D. W. \& Sullivan, K. F. (1985). Molecular biology and genetics of tubulin. Annual Review of Biochemistry 54, 331-365.

DavidSE, L. C. \& FlaCh, W. (1977). Differential binding of methyl benzimidazol-2-yl carbamate to fungal tubulin as a mechanism of resistance to this antimitotic agent in mutant strains of Aspergillus nidulans. Journal of Cell Biology 72, 174-193.

EDWARDS, P. Q. (1971). Histoplasmin sensitivity patterns around the world. In Histoplasmosis: Proceedings of the Second National Conference, pp. 97102. Edited by L. Ajello, E. W. Chick \& M. D. Furcolow. Springfield: Charles C. Thomas.

EMmons, C. W., Binford, C. H., Utz, J. P. \& KWonChung, K. J. (1977). Medical Mycology. Philadelphia: Lea \& Febiger.

GraybiLl, J. R. (1988). Histoplasmosis and AIDS. Journal of Infectious Diseases 158, 623-626.

Harris, G. S., Keath, E. J. \& Medoff, J. (1989). Expression of $\alpha$ - and $\beta$-tubulin genes during dimorphic-phase transitions of Histoplasma capsulatum. Molecular and Cellular Biology 9, 2042-2049.

Hiraoka, Y., Toda, T. \& Yanagida, M. (1984). The $N D A 3$ gene of fission yeast encodes beta tubulin: a cold-sensitive nda3 mutation reversibly blocks spindle formation and chromosome movement in mitosis. Cell 39, 349-358.

Kirkland, W. L. \& Burton, P. R. (1972). Cyclic adenosine monophosphate-mediated stabilization of mouse neuroblastoma cell neurite microtubules exposed to low temperature. Nature New Biology 240 , 205-207.

KRAM, R. \& ToMkins, G. M. (1973). Pleiotypic control of cyclic AMP: interaction with cyclic GMP and possible role of microtubules. Proceedings of the National Academy of Sciences of the United States of America 70, 1659-1663.

Krauhs, E., Little, M., Kempf, T., HoferW arbinek, R., Ade, W. \& Ponstingl, H. (1981). Complete amino acid sequence of beta tubulin from porcine brain. Proceedings of the National Academy of Sciences of the United States of America 78, 41564160 .

Langford, C. J., Klniz, F. J., Donath, C. \& Gallwitz, D. (1984). Point mutations identify the conserved, intron-contained TACTAAC box as an essential splicing signal sequence in yeast. Cell 36, 645-653.

LaRsen, A. D. \& SYPherd, P. S. (1974). Cyclic adenosine $3^{\prime}, 5^{\prime}$-monophosphate and morphogenesis in Mucor racemosus. Journal of Bacteriology 117, 432438.

LEBERMAN, R. \& EGNER, U. (1984). Homologies in the primary structure of GTP-binding proteins: the nucleotide binding site of EF-Tu and p21. EMBO Journal 3, 339-341.

Maniatis, T., Fritsch, E. F. \& Sambrook, J. (1982). In Molecular Cloning: a Laboratory Manual. Cold Spring Harbor, NY: Cold Spring Harbor Laboratory.

Maresca, B., Medoff, G., Schlessinger, D., Kobayashi, G. S. \& Medoff, J. (1977). Regulation of dimorphism in the pathogenic fungus Histoplasma capsulatum. Nature, London 266, 447-448.

May, G. S., Tsang, M. L. S., Smith, H., Fidel, S. \& MORRIS, N. R. (1987). Aspergillus nidulans beta tubulin genes are unusually divergent. Gene 55, 231243.

Medoff, J., Jacobson, E. \& Medoff, G. (1981). Regulation of dimorphism in Histoplasma capsulatum by cyclic adenosine $3^{\prime}, 5^{\prime}$-monophosphate. Journal of Bacteriology 145, 452-1455.

Medoff, J. \& Medoff, G. (1982). Microtubules are involved in the phase transition of Histoplasma capsulatum. Journal of Cell Biology 95, 44a. 
Medoff, G., Kobayashi, G. S., Painter, A. \& Travis, S. (1987). Morphogenesis and pathogenicity of Histoplasma capsulatum. Infection and Immunity 55, 1355-1358.

Mount, S. M. (1982). A catalogue of splice junction sequences. Nucleic Acids Research 10, 459-472.

NefF, N. F., Thomas, J. H., Grisafi, P. \& Botstein, D. (1983). Isolation of the beta tubulin gene from yeast and demonstration of its essential function in vivo. Cell 33, 211-219.

Nimi, M., Nimi, K., Tokunaga, J. \& Nakayami, H. (1980). Changes in cyclic nucleotide levels and dimorphic transition in Candida albicans. Journal of Bacteriology 142, 1010-1014.

Orbach, M. J., Porro, E. B. \& Yanofsky, C. (1986). Cloning and characterization of the gene for beta tubulin from a benomyl-resistant mutant of Neurospora crassa and its use as a dominant selectable marker. Molecular and Cellular Biology 6, 2452-2461.

Paveto, C., EPStein, A. \& Passeron, S. (1975). Studies on cyclic adenosine $3^{\prime}, 5^{\prime}$-monophosphate levels, adenylate cyclase, and phosphodiesterase activities in the dimorphic fungus Mucor rouxii. Archives of Biochemistry and Biophysics 169, 449-457.

Porter, K. R., Puck, T. T., Hsie, A. W. \& Kelley, D. (1974). An electron microscopy study of the effects of dibutyryl cyclic AMP on chinese hamster ovary cells. Cell 2, 145-162.

Rigby, P. W. J., Dieckman, M., Rhodes, C. \& Berg, P. (1977). Labeling deoxyribonucleic acid to high specific activity in vitro by nick translation with DNA polymerase I. Journal of Molecular Biology 113, 237-251.

Ruskin, B., Krainer, A. R., Maniatis, T. \& Green, M. R. (1984). Excision of an intact intron as a novel lariat structure during pre-mRNA splicing in vitro. Cell 38, 317-338.

SALVIN, S. B. (1949). Growth of the yeast-like phase of Histoplasma capsulatum in a fluid medium. Journal of Bacteriology 59, 312-313.

SANGer, F., Nicklen, S. \& Coulson, A. R. (1977). DNA sequencing with chain terminating inhibitors. Proceedings of the National Academy of Sciences of the United States of America 74, 5463-5467.

Schatz, P. J., Pillus, L., Grisafi, P., Solomon, F. \& Botstein, D. (1986). Two functional alpha tubulin genes of the yeast Saccharomyces cerevisiae encode divergent proteins. Molecular and Cellular Biology 6, 3711-3721.

Schatz, P. J., Georges, G. E., Solomon, F. \& BotsteIN, D. (1987). Insertions of up to 17 amino acids into a region of alpha tubulin do not disrupt function in vivo. Molecular and Cellular Biology 7, 3799-3805.

Schedl, T., OWens, J., Dove, W. F. \& Burland, T. G. (1984). Genetics of the tubulin gene families of Physarum. Genetics 108, 143-164.

SchwaRTZ, D. C. \& CaNTOR, C. R. (1984). Separation of yeast chromosome-sized DNAs by pulsed field gradient gel electrophoresis. Cell 37, 67-75.

Serrano, L., Avila, J. \& Maccione, R. (1984a). Controlled proteolysis of tubulin by subtilisin: localization of the site for $\mathrm{MAP}_{2}$ interaction. Biochemistry 23, 4675-4681.

Serrano, L., Torre, J., Maccioni, R. \& Avila, J. $(1984 b)$. Involvement of the carboxy-terminal domain of tubulin in the regulation of its assembly. Proceedings of the National Academy of Sciences of the United States of America 81, 5989-5993.

Silflow, C. D. \& Rosenbaum, J. L. (1981). Multiple alpha and beta tubulin genes in Chlamydomonas and regulation of tubulin mRNA levels after deflagellation. Cell 24, 81-88.

Silflow, C. D., Chisholm, R. L., Conner, T. W. \& Ranum, L. P. W. (1985). The two alpha tubulin genes of Chlamydomonas reinhardii code for slightly different proteins. Molecular and Cellular Biology $\mathbf{5}$, 2389-2398

SoutherN, E. M. (1975). Detection of specific sequences among DNA fragments separated by gel electrophoresis. Journal of Molecular Biology 98, 503-517.

Steele, P. E., Carle, G. F., Kobayashi, G. S. \& MEDOFF, G. (1989). Electrophoretic analysis of Histoplasma capsulatum chromosomal DNA. Molecular and Cellular Biology 9, 983-987.

Steiner, M. (1978). 3',5'-Cyclic AMP binds to and promotes polymerization on platelet tubulin. Nature, London 272, 834-835.

Toda, T., Adachi, Y., Hiraoka, Y. \& Yanagida, M. (1984). Identification of the pleiotropic cell division cycle gene $N D A 2$ as one of two different alpha tubulin genes in Schizosaccharomyces pombe. Cell 37, 233-242.

Weatherbee, J. A. \& Morris, N. R. (1984). Aspergillus contains multiple tubulin genes. Journal of Biological Chemistry 259, 15452-15459.

WEISENBERG, R. C. (1972). Microtubule formation in vitro in solutions containing low calcium concentrations. Science 177, 1104-1105.

Youngblom, J., Schloss, J. \& Silflow, C. D. (1984). The two beta tubulin genes of Chlamydomonas reinhardii code for identical proteins. Molecular and Cellular Biology 4, 2686-2696. 